\title{
Quantitative phase analysis in the assessment of coronary artery disease
}

\author{
S R UNDERWOOD, S WALTON, P J LAMING, P J ELL, R W EMANUEL, \\ R H SWANTON
}

From the Middlesex Hospital and Medical School, London

SUMMARY The phase image in radionuclide ventriculography shows the timing of ventricular contraction and is valuable in the detection of abnormalities induced by coronary artery disease. $\frac{7}{\sigma}$ The image is usually interpreted subjectively, and in the present study a histogram of left:ventricular phase values was used to make interpretation more objective. The left ventricular ejection fraction and the standard deviation, skewness, and kurtosis of the phase histogram were $e_{\circ}^{+}$ measured at rest, during isometric exercise, and during the final two stages of maximal dynamic exercise in 25 controls and 27 patients with coronary artery disease without previous infarction. $\vec{c}$ The ejection fraction and the standard deviation of the phase had the same predictive accuracy for? the presence of disease when measured during the penultimate stage of dynamic exercise $(89 \%)$ as during the final stage, but their accuracy was lower during maximal exercise $(77 \%)$ because of motion artefact at high exercise levels. Skewness and kurtosis of the histogram were of no value for the detection of disease, and isometric exercise was of only limited value.

It is concluded that the phase histogram provides an objective measurement of the synchronicity of left ventricular contraction and can increase sensitivity for the detection of abnormality. Datas should be acquired at all stages of dynamic exercise, and the penultimate stage should be used ifo there is any doubt about the validity of the final stage.

Radionuclide ventriculography provides a simple method of assessing global and regional left ventricular function at rest and during exercise. The response of the left ventricular ejection fraction to maximal dynamic exercise has been shown to be useful in the detection of coronary artery disease, ${ }^{1}$ although it also has an important role in the assessment of the significance of established disease. ${ }^{23}$ An abnormal ejection fraction response is usually the result of regional wall motion abnormalities, which can be assessed objectively using the Fourier phase and amplitude images. ${ }^{4}$ These images are derived from the cineventriculogram and they indicate the timing and magnitude of count changes (hence wall motion) at each point over the heart.

Phase approximates to the time of end systole expressed as a percentage of the total cardiac cycle, and abnormalities occur commonly in coronary artery disease. ${ }^{5}$ The phase image is particularly valuable because abnormalities of the timing of

Requests for reprints to Dr S R Underwood, Magnetic Resonance Unit, The National Heart and Chest Hospitals, 30 Britten Street, London SW3 6NN.

Accepted for publication 31 May 1988 contraction are difficult to detect by viewing the $\overline{\bar{B}}$ cineventriculogram alone. The purpose of this work is to investigate the role of quantitative analysis of the phase image as a method of improving upon subjective interpretation. Although quantitative phase ${ }_{\overparen{\infty}}^{\vec{\gamma}}$ analysis has been studied before in patients with $\frac{\stackrel{\varrho}{7}}{7}$ coronary artery disease, there are conflicting reports ${ }_{0}-\overrightarrow{-}$ of its value. ${ }^{6-9}$ The conflict arises partly because of 3 . different patient populations and so we have confined this study to patients with known coronary artery disease but without infarction, since these are the $O$ patients in whom the question of stress induced left ventricular dysfunction commonly arises. We haveo also extended the findings of previous studies by comparing the effects of isometric exercise, $N$ submaximal dynamic exercise, and maximal dynamicn exercise.

Because all parts of the left ventricle should ${ }^{\omega}$ contract with the same timing, the normal left ventricular phase histogram consists of a single narrow peak. Myocardial ischaemia leads to areas of delayed contraction which broaden the peak, and should be reflected in the standard deviation of this ${ }^{-}$ histogram. Skewness and kurtosis are other, 


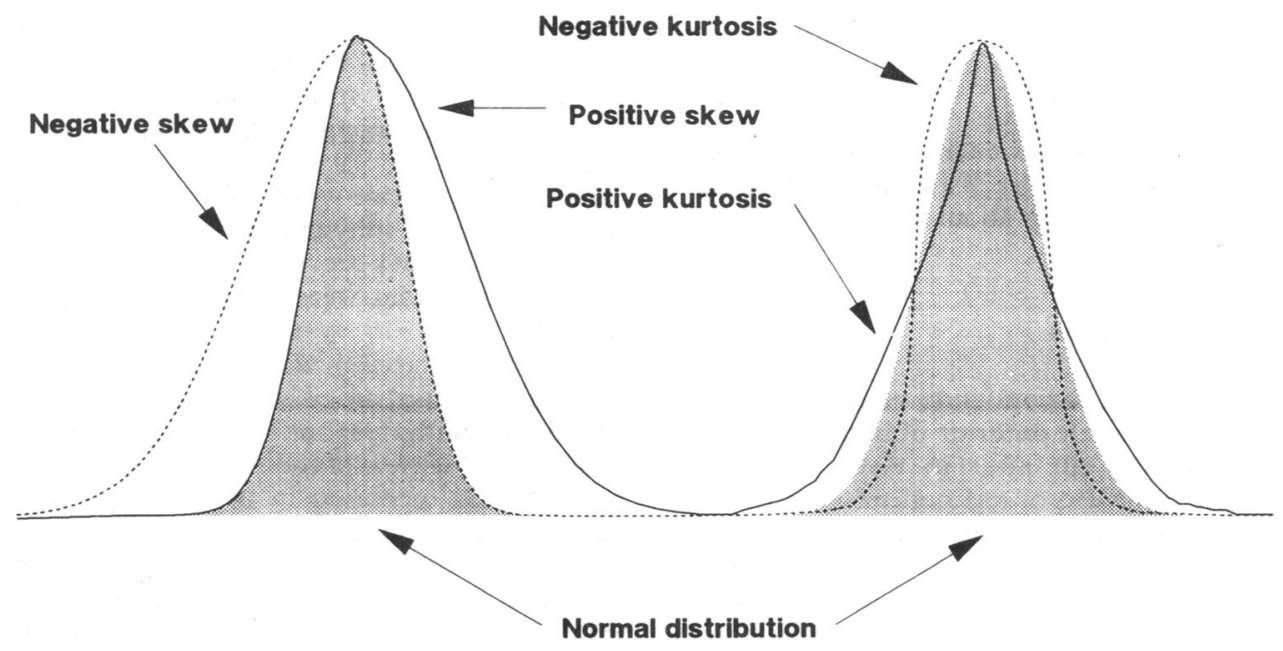

Fig 1 Curves showing positive and negative skewness (left), and positive and negative kurtosis (right). The reference curve (shaded area) is a normal distribution which has zero skewness and kurtosis.
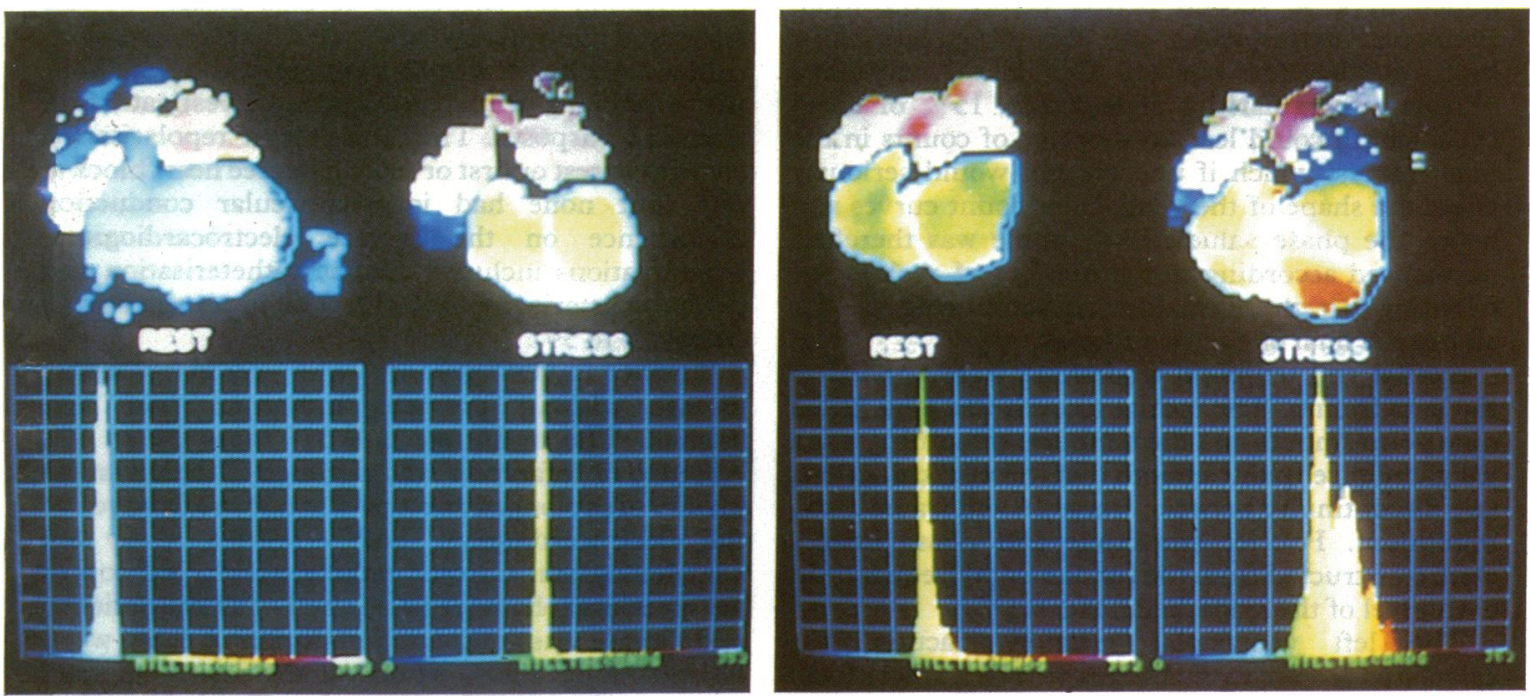

Fig 2 Phaise images and histograms at rest and during maximal dynamic exercise in a normal subject (left) and a patient with disease of the left anterior descending coronary artery (right).

parameters of shape that are of potential interest. Skewness is a measure of the symmetry of a distribution, and it is defined as the difference between the mean and the mode expressed as a fraction of the standard deviation. ${ }^{10}$

$$
\text { Skew }=(\text { mean }- \text { mode }) / \text { standard deviation }
$$

A tail of high values in a distribution produces a skew to the right (positive skewness) and a tail of low values produces a skew to the left (negative skewness). Kurtosis is a measure of whether a distribution has a wide base with a narrow and sharp peak (leptokurtic) or a relatively narrow base with a flat topped peak (platykurtic) (fig 1). It is calculated from the fourth and second moments of the distribution about its mean $(m)^{11}$ :

$$
\text { Kurtosis }=\left[\mu_{4}(\mathrm{~m}) / \mu_{2}(\mathrm{~m})^{2}\right]-3
$$


where the nth moment about a point (a) is:

$$
\mu_{n}(a)=\sum_{i}\left[\left(x_{i}-a\right)^{n}\right] / N
$$

When $a=0$, the first moment about the origin .$\left(\mu_{1}(0)\right)$ is the mean $(m)$ of the distribution, and when $\mathrm{a}=\mathrm{m}$, the second moment about the mean $\left(\mu_{2}(\mathrm{~m})\right)$ is the variance $\left(\mathrm{SD}^{2}\right)$.

\section{Patients and methods}

Resting equilibrium radionuclide ventriculography was performed in a left anterior oblique projection with $30^{\circ}$ of caudal tilt after in vivo erythrocyte labelling with $740 \mathrm{MBq}$ of technetium-99m sodium pertechnetate. A General Electric Portacamera IIC with a $200 \mathrm{~mm}$ field of view was used, interfaced to an Informatek Simmis III computer. Sixteen frames per cardiac cycle were acquired with 320000 counts per frame. Arrhythmia rejection was used to reject data from the cycle following one of length more than $15 \%$ from the mean cycle length, which was determined in a 30 second period before acquisition. Premature extrasystoles and the subsequent sinus beat were therefore rejected. Despite this arrythmia rejection, irregularities of less than $15 \%$ of mean cycle length could lead to shortage of counts in the final frames, which if uncorrected would seriously affect the shape of the ventricular count curves and hence the phase values. Each frame was therefore normalised according to the number of cycles contributing to it, the normalisation factor being one, for all but the final one or two frames.

Spatial and temporal smoothing were applied to the data frames. The spatial smooth was a weighted nine point smooth and the temporal smoothing was a weighted three point smooth that was cyclical, so that any discontinuity between frame 16 and frame 1 was minimised. Fourier amplitude and phase images were constructed from the fundamental frequency in each pixel of the smoothed images.

The left ventricular ejection fraction was calculated from count changes within a single fixed left ventricular region of interest that was assigned manually on the end diastolic frame with the aid of the end systolic frame and the amplitude and phase images which assisted with definition of the valve planes. The raw data frames were used for this calculation with an automatic functional background subtraction, which was described by Goris et al. ${ }^{12}$ This method of background subtraction is operator independent and background counts are calculated from the data frames on the assumption that pixels with positive stroke counts are ventricular pixels and those with zero stroke counts are background. Pixels with negative stroke counts. (atria and great vessels)

are ignored. This method is known to be reliable in patients with good ventricular function (as in all $\stackrel{\leftarrow}{\hookrightarrow}$ patients in this study) although it may be $\overrightarrow{\vec{F}}$. less accurate in patients with very poor ventricular function. ${ }^{12}$

Isometric exercise was performed by squeezing a $\frac{\bar{c}}{\bar{c}}$ partially inflated sphygmomanometer cuff for three $\frac{\vec{\sigma}}{\vec{\alpha}}$ minutes at $30 \%$ of a previously established maximum $\propto$ pressure, and data were acquired in the final two कै minutes.

Dynamic exercise was performed by supine $\stackrel{-}{-}$ subjects on a mechanically braked bicycle. Shoulder $\vec{\omega}$ restraints, handgrips, and chest straps were used to $\stackrel{\odot}{\rightarrow}$ minimise movement of the chest. Exercise was begun at $25 \mathrm{~W}$ and increased in $25 \mathrm{~W}$ stages with three ${ }_{-}$. minutes at each stage. Data were acquired in the final two minutes of each stage. Patients stopped because $\vec{A}$ of fatigue, pain, or dyspnoea. Important arrhythmia 0 or fall in blood pressure did not occur in any patient.

We studied 25 controls; four were volunteers ${ }_{C}$ under the age of 35 without symptoms or signs of heart disease. The remainder were undergoing $\frac{c}{0}$ investigation for suspected cardiac disease but no structural abnormality was found. Fifteen had chest $\vec{\omega}$ pain and six had electrocardiographic abnormalities, $\infty$ the latter being in aircrew requiring investigation for ${ }^{\circ}$ licensing purposes. They were either repolarisation 0 changes at rest or first or second degree heart block at rest, but none had intraventricular conduction disturbance on the surface electrocardiogram. Investigations included cardiac catheterisation and $\stackrel{\odot}{\mathscr{Q}}$ coronary arteriography in 17 . The mean age was $40 \overrightarrow{\vec{\rho}}$ (range 22 to 59 ).

Twenty seven patients with coronary artery disease without previous infarction were also studied. The mean age was 51 (range 30 to 65). Absence of infarction was assumed if there was no $\mathbb{D}$ history of prolonged chest pain at rest, no $Q$ waves on the electrocardiogram, and a normal $x$ ray left ventriculogram. Cardiac catheterisation and coronary arteriography were performed in all the patients, and disease was considered important if there was a narrowing of $>50 \%$ of one of the major coronary을 arteries or their proximal branches. Two patients had $>$ three vessel disease with additional disease of the left 으․ main coronary artery, 10 had three vessel disease, $13 \stackrel{\mathrm{N}}{\mathrm{N}}$ had two vessel disease, and two had single vessel o disease. The left anterior descending artery was $N$ affected in 24, the left circumflex in 22, and the right $\mathrm{W}_{\mathrm{J}}$ coronary artery in 18.

The subjects were studied at rest, during isometric exercise, and during the final two stages of a symptom limited dynamic exercise test (later referred to as $\stackrel{-}{+}$ submaximal and maximal exercise). $\beta$ Blockade was $\square$ stopped at least $\mathbf{4 8}$ hours before the study and other $\overline{0}$ cardioactive drugs were stopped 12 hours before. 
Data were available for all subjects at rest and at maximum exercise but, because some were recruited retrospectively, data during isometric exercise were available in only 12 of the normal subjects and 18 of the patients, and during submaximal exercise in 20 normal subjects and 15 patients. At each stage the following measurements were made: left ventricular ejection fraction; mean left ventricular phase; and the standard deviation, skewness, and kurtosis of the left ventricular phase histogram. The histogram was constructed from the number of pixels within $3^{\circ}$ ranges.

\section{Results}

\section{EXERCISE DATA}

Mean peak exercise level was $155 \mathrm{~W}$ (range 125 to 200 W) for the normal subjects and $98 \mathrm{~W}$ (range 50 to 175 W) for the patients with coronary artery disease. Eighty five percent of maximal predicted heart rate was achieved in 20 of the 25 controls but in only four of the 27 patients. Dynamic exercise was limited by shortness of breath or fatigue in all of the normal subjects and by chest pain in 14 of the patients, fatigue in six, shortness of breath in three, and claudication in two. No controls and only one patient experienced chest pain during isometric exercise.

Table 1 summarises the haemodynamic changes. The patients with coronary artery disease had a slightly higher resting heart rate than the normal subjects $(\mathrm{p}<0.05)$ but at maximal exercise the normal subjects achieved a very much higher rate than the patients $(p<0.001)$. Both groups increased heart rate in response to isometric exercise, and blood pressure increased at all levels of stress. There were no significant differences in blood pressure at any level of stress between the two groups.

Table 1 Mean (SD) of the pulse rate (beats/min) and systolic and diastolic blood pressures $(B P)(\mathrm{mm} \mathrm{Hg})$ at rest, during isometric exercise (grip), and during maximal supine dynamic exercise (stress)

\begin{tabular}{|c|c|c|c|c|}
\hline & \multicolumn{2}{|c|}{ Controls } & \multicolumn{2}{|c|}{ Coronary artery disease } \\
\hline & Mean & $S D$ & Mean & $S D$ \\
\hline $\begin{array}{l}\text { Rest: } \\
\text { Pulse } \\
\text { Systolic BP } \\
\text { Diastolic BP }\end{array}$ & $\begin{array}{c}67 \cdot 5 \\
138 \\
89\end{array}$ & $\begin{array}{l}9 \cdot 4 \\
8 \cdot 2 \\
9 \cdot 0\end{array}$ & $\begin{array}{c}74.9 \\
138 \\
93\end{array}$ & $\begin{array}{l}13.8 \\
22.7 \\
12.7\end{array}$ \\
\hline $\begin{array}{l}\text { Grip: } \\
\text { Pulse } \\
\text { Systolic BP } \\
\text { Diastolic BP }\end{array}$ & $\begin{array}{c}75 \cdot 2 \\
157 \\
103\end{array}$ & $\begin{array}{r}7 \cdot 4 \\
11 \cdot 1 \\
7 \cdot 9\end{array}$ & $\begin{array}{c}84 \cdot 2 \\
159 \\
105\end{array}$ & $\begin{array}{r}6 \cdot 2 \\
26 \cdot 3 \\
14 \cdot 8\end{array}$ \\
\hline $\begin{array}{l}\text { Stress: } \\
\text { Pulse } \\
\text { Systolic BP } \\
\text { Diastolic BP }\end{array}$ & $\begin{array}{l}156 \\
184 \\
103\end{array}$ & $\begin{array}{l}21 \cdot 7 \\
20 \cdot 5 \\
13.5\end{array}$ & $\begin{array}{l}117 \\
180 \\
104\end{array}$ & $\begin{array}{l}19.9 \\
24.2 \\
15.0\end{array}$ \\
\hline
\end{tabular}

Table 2 Mean (SD) for variables measured at rest, during isometric exercise (grip), and the penultimate (submaximal) and ultimate (maximal) stages of dynamic exercise on the left ventricular phase histogram

\begin{tabular}{|c|c|c|c|c|c|c|c|}
\hline & \multicolumn{3}{|l|}{ Controls } & \multicolumn{4}{|c|}{ Coronary artery disease } \\
\hline & Mean & $S D$ & No & Aean & $S D$ & No & $p^{\star}$ \\
\hline \multicolumn{8}{|c|}{ Rest } \\
\hline $\begin{array}{l}\text { F (\%) } \\
\text { hase } \\
D^{\circ} \dagger \\
\text { tewness }\end{array}$ & $\begin{array}{c}64 \\
131 \\
8 \cdot 3 \\
-0 \cdot 11 \\
3 \cdot 3\end{array}$ & $\begin{array}{c}10 \cdot 1 \\
15 \cdot 3 \\
3 \cdot 5 \\
0 \cdot 36 \\
3 \cdot 4\end{array}$ & $\begin{array}{l}25 \\
25 \\
25 \\
25 \\
25 \\
G\end{array}$ & $\begin{array}{c}61 \\
143 \\
10.6 \\
-0.04 \\
4.3\end{array}$ & $\begin{array}{c}10 \cdot 2 \\
18 \cdot 2 \\
3 \cdot 5 \\
0.52 \\
4 \cdot 6\end{array}$ & $\begin{array}{l}27 \\
27 \\
27 \\
27 \\
27\end{array}$ & $\begin{array}{l}\text { NS } \\
<0.01 \\
<0.02 \\
\text { NS } \\
\text { NS }\end{array}$ \\
\hline $\begin{array}{l}\text { EF (\%) } \\
\text { Phase } \\
\text { SD'† } \\
\text { Skewness } \\
\text { Kurtosis }\end{array}$ & $\begin{array}{c}66 \\
139 \\
7.9 \\
-0.06 \\
3.4\end{array}$ & $\begin{array}{c}11 \cdot 2 \\
17 \cdot 6 \\
2 \cdot 2 \\
0.34 \\
2 \cdot 4\end{array}$ & $\begin{array}{l}12 \\
12 \\
12 \\
12 \\
12\end{array}$ & $\begin{array}{c}60 \\
154 \\
10.7 \\
-0.06 \\
2.7\end{array}$ & $\begin{array}{c}8 \cdot 2 \\
18 \cdot 9 \\
3 \cdot 8 \\
0.39 \\
3 \cdot 2\end{array}$ & $\begin{array}{l}8 \\
8 \\
8\end{array}$ & $\begin{array}{l}\text { NS } \\
<0.05 \\
<0.02 \\
\text { NS } \\
\text { NS }\end{array}$ \\
\hline $\begin{array}{l}\text { EF (\%) } \\
\text { Phase } \\
\text { SD } D^{\circ} \\
\text { Skewness } \\
\text { Kurtosis }\end{array}$ & $\begin{array}{c}75 \\
153 \\
7 \cdot 6 \\
-0 \cdot 10 \\
2 \cdot 2\end{array}$ & $\begin{array}{c}\text { Sulom } \\
7 \cdot 2 \\
16 \cdot 5 \\
2 \cdot 3 \\
0.45 \\
2 \cdot 2\end{array}$ & $\begin{array}{l}23 \\
20 \\
20 \\
20 \\
20 \\
20\end{array}$ & $\begin{array}{c}58 \\
145 \\
15.9 \\
-0.29 \\
2.7 \\
\text { cercise }\end{array}$ & $\begin{array}{c}12 \cdot 2 \\
16 \cdot 6 \\
7 \cdot 30 \\
0.42 \\
3 \cdot 2\end{array}$ & $\begin{array}{l}15 \\
15 \\
15 \\
15 \\
15\end{array}$ & $\begin{array}{l}<0.001 \\
\text { NS } \\
<0.001 \\
\text { NS } \\
\text { NS }\end{array}$ \\
\hline $\begin{array}{l}\text { EF } \\
\text { Pha } \\
\text { SD } \\
\text { Ske } \\
\text { Ku }\end{array}$ & $\begin{array}{c}73 \\
156 \\
8.9 \\
-0.08 \\
2.0 \\
C h\end{array}$ & $\begin{array}{c}8.4 \\
16 \cdot 5 \\
4 \cdot 3 \\
0.42 \\
3.5 \\
\text { hanges } b\end{array}$ & $\begin{array}{l}25 \\
25 \\
25 \\
25 \\
25 \\
\text { etween }\end{array}$ & $\begin{array}{c}60 \\
153 \\
15.3 \\
-0.04 \\
2.5 \\
\text { rest and st }\end{array}$ & $\begin{array}{c}15 \cdot 4 \\
18 \cdot 6 \\
8 \cdot 2 \\
0.44 \\
3.5 \\
\text { tress }\end{array}$ & $\begin{array}{l}27 \\
27 \\
27 \\
27 \\
27\end{array}$ & $\begin{array}{l}<0.001 \\
\text { NS } \\
<0.001 \\
\text { NS } \\
\text { NS }\end{array}$ \\
\hline Grip. & $\begin{array}{l}2.0 \\
0.6 \\
0.02 \\
0.80\end{array}$ & $\begin{array}{l}1.6 \\
0.49 \\
2.9\end{array}$ & $\begin{array}{l}12 \\
12 \\
12\end{array}$ & $\begin{array}{c}-0.8 \\
0.2 \\
0.00 \\
-1.6\end{array}$ & $\begin{array}{l}2.5 \\
0.63 \\
5.5\end{array}$ & 8 & NS \\
\hline Sub & exerc & & & & & & \\
\hline $\begin{array}{l}\text { EF }(\%) \\
\text { SD } \% \\
\text { Skewness } \\
\text { Kurtosis }\end{array}$ & $\begin{array}{c}11.0 \\
-0.6 \\
0.03 \\
-0.7\end{array}$ & $\begin{array}{l}7 \cdot 4 \\
3 \cdot 1 \\
0 \cdot 50 \\
2 \cdot 2\end{array}$ & $\begin{array}{l}23 \\
20 \\
20 \\
20\end{array}$ & $\begin{array}{c}-3.0 \\
4.4 \\
-0.26 \\
-1.3\end{array}$ & $\begin{array}{l}7 \cdot 2 \\
5 \cdot 7 \\
0 \cdot 49 \\
3 \cdot 4\end{array}$ & $\begin{array}{l}15 \\
15\end{array}$ & $\begin{array}{l}<0.001 \\
<0.01 \\
\text { NS } \\
\text { NS }\end{array}$ \\
\hline & & & & & & & \\
\hline $\begin{array}{l}\text { EF (\%) } \\
\text { SD }+ \\
\text { Skewness } \\
\text { Kurtosis }\end{array}$ & $\begin{array}{c}9.0 \\
0.5 \\
0.03 \\
-1.3\end{array}$ & $\begin{array}{l}10.3 \\
4.6 \\
0.50 \\
5.0\end{array}$ & $\begin{array}{l}25 \\
25 \\
25 \\
25\end{array}$ & $\begin{array}{c}-1.0 \\
4.7 \\
0.00 \\
-1.8\end{array}$ & $\begin{array}{c}13 \cdot 5 \\
7 \cdot 4 \\
0.50 \\
5 \cdot 0\end{array}$ & $\begin{array}{l}27 \\
27\end{array}$ & $\begin{array}{l}<0.01 \\
<0.02 \\
\text { NS } \\
\text { NS }\end{array}$ \\
\hline
\end{tabular}

*Statistical significance of difference between means for controls and patients with coronary heart disease; + Standard deviation of phase histogram. EF, left ventricular ejection fraction.

\section{EJECTION FRACTION}

Table 2 shows the ejection fraction and phase histogram data in the two groups. The probability values given are for the differences between the means of the two groups by Student's $t$ test. There was no significant difference between the mean resting left ventricular ejection fractions of the two groups at rest, but at submaximal and at maximal dynamic exercise there were large differences. Mean ejection fraction rose from $64 \%$ to $73 \%$ in the normal subjects $(p<0.01)$ whereas it fell from $61 \%$ to $60 \%$ in the patients $(p=N S)$. If a normal response to dynamic exercise is taken to be an increase in ejection fraction of $\geqslant 5$ percentage units, ${ }^{13}$ the sensitivity, specificity, and predictive accuracy of ejection fraction for the detection of disease were $85 \%, 68 \%$, 
18

Table 3 Sensitivities, specificities, and predictive accuracies for the detection of coronary artery disease from the response to isometric exercise (grip), submaximal dynamic exercise, and maximal dynamic exercise with the following criteria for normality: change in ejection fraction $(E F) \geqslant 5 \%$, standard deviation (SD) of the phase histogram $\leqslant 10^{\circ}$, normal ejection fraction response, and standard deviation.

\begin{tabular}{lcrl}
\hline & Sensitivity & Specificity & $\begin{array}{l}\text { Predictive } \\
\text { accuracy }\end{array}$ \\
\hline Grip EF & $15 / 18(83 \%)$ & $4 / 12(33 \%)$ & $19 / 30(63 \%)$ \\
Submaximal EF & $13 / 15(87 \%)$ & $21 / 23(91 \%)$ & $34 / 38(89 \%)$ \\
Maximal EF & $23 / 27(85 \%)$ & $17 / 25(68 \%)$ & $40 / 52(77 \%)$ \\
Grip SD & $9 / 18(50 \%)$ & $11 / 12(92 \%)$ & $20 / 30(67 \%)$ \\
Submaximal SD & $13 / 15(87 \%)$ & $18 / 20(90 \%)$ & $31 / 35(89 \%)$ \\
Maximal SD & $22 / 27(81 \%)$ & $20 / 27(74 \%)$ & $42 / 54(78 \%)$ \\
Grip EF+ SD & $16 / 18(89 \%)$ & $4 / 12(33 \%)$ & $20 / 30(67 \%)$ \\
Submaximal EF+ SD & $15 / 15(100 \%)$ & $16 / 20(80 \%)$ & $31 / 35(89 \%)$ \\
Maximal EF + SD & $25 / 27(93 \%)$ & $15 / 27(56 \%)$ & $40 / 54(74 \%)$ \\
\hline ‡True positives + true negatives/number of test. &
\end{tabular}

and $77 \%$ respectively at maximum exercise and $87 \%$, $91 \%$, and $89 \%$ at submaximal exercise (table 3 ).

\section{PHASE}

At rest, the patients with coronary artery disease had a slightly higher mean left ventricular phase and standard deviation of phase than normal $(p<0.01$ and 0.02 respectively). This is surprising in view of the fact that none of the patients had evidence of previous infarction, but visual inspection of the amplitude and phase images showed definite abnormalities at rest in six patients and possible abnormalities in a further two. The standard deviation of phase was $>10^{\circ}$ in 12 patients and in six controls, giving a sensitivity and specificity for the detection of disease at rest of $44 \%$ and $24 \%$ respectively. These figures are inadequate for the phase image at rest to be useful for the detection of disease, but it can be concluded that phase analysis of the radionuclide ventriculogram is more sensitive than subjective reporting of the $x$ ray contrast ventriculogram in the detection of abnormal ventricular wall motion (the contrast ventriculograms were all considered to be normal).

.The mean phase did not differ between the two groups at maximal or submaximal exercise because higher heart rates were achieved in the normal group. There were large differences, however, in the mean standard deviation of phase. This was almost unchanged with exercise in the normal subjects, increasing from $8.4^{\circ}$ to $8.9^{\circ}(p=N S)$, but in the patients it increased significantly from $10.6^{\circ}$ to $15.3^{\circ}$ $(p<0.02)$. With an arbitrary criterion for normality for the standard deviation of phase as $S D \leqslant 10^{\circ}$, the sensitivity, specificity, and predictive accuracy for the detection of disease are $81 \%, 74 \%$, and $78 \%$ respectively at maximal exercise, and $87 \%, 90 \%$, and
Underwood, Walton, Laming, Ell, Emanuel, Swanton $89 \%$ at submaximal exercise (table 3 ). Visual interpretation of the images showed abnormalities in only $17(63 \%)$ of the 27 patients, indicating that quantitative measurement from the image is more sensitive than visual inspection alone.

\section{SKEWNESS AND KURTOSIS}

At no stage of exercise (isometric and dynamic) were there any significant changes in skewness or kurtosis in either group, nor were there any differences between the groups.

\section{ISOMETRIC EXERCISE}

There were significant differences in mean phase and in the standard deviation of phase between the two groups during isometric exercise, but the means did not change between rest and isometric exercise and these differences reflect the resting abnormalities. In three of the patients, however, the standard deviation of phase was normal at rest but became abnormal during isometric exercise. This did not occur in any of the controls and it suggests that the development of new wall motion abnormalities during isometric exercise is highly specific for the presence of disease.

\section{EXAMPLES}

To illustrate the changes described above, fig 2 shows the phase images and phase histogram at rest and at maximal dynamic exercise in a normal subject and in a patient with disease of the left anterior descending coronary artery. The normal subject was a pilot in the Royal Air Force who played regular squash and who had $T$ wave inversion in a resting electrocardiogram. He had a resting bradycardia (55/minute) and the resting phase was low $\left(109^{\circ}\right)$ with a narrow phase histogram $\left(S D 6 \cdot 7^{\circ}\right)$. On exercise, he reached a peak rate of $172 /$ minute and mean phase increased to $143^{\circ}$, but the phase histogram remained narrow (SD $5 \cdot 2^{\circ}$ ). The increase in phase is reflected in the change from blue to green in the display.

The patient had angina without previous myocardial infarction and the resting phase image was normal with mean phase $138^{\circ}$ and standard deviation $9 \cdot 6^{\circ}$ (close to the upper limit of normal). On exercise, he reached $125 \mathrm{~W}$ before stopping with angina at a rate of $138 /$ minute. The phase image became clearly abnormal with very high values at the apex and a standard deviation of $31^{\circ}$. The phase over the basal part of the ventricle also increased because of the tachycardia. Despite these phase changes, the amplitude image was relatively unchanged.

\section{Discussion}

We have shown that the response of the ejection fraction to dynamic exercise is sensitive and specific 
in the detection of coronary artery disease, with a predictive accuracy of $89 \%$ in the population studied. This accords with the findings of several previous studies. ${ }^{14-17}$ We have also shown that the standard deviation of the phase histogram has an equal predictive accuracy if a normal value is taken to be $10^{\circ}$ or less. The sensitivity of the phase histogram is not unexpected because the ejection fraction is abnormal because of regional abnormalities of wall motion, which should be reflected in the phase image. The abnormalities were apparent from visual inspection of the phase image alone in $63 \%$ of cases, but the quantitative measurement of standard deviation increased sensitivity. This does not imply that the phase image is redundant, rather that the phase image and the phase histogram should be considered together. The histogram does not give any regional information and if the standard deviation of phase is abnormal then the affected area can be localised on the phase image.

There are previous studies of the phase histogram in health and disease. Our findings accord with those of Ratib et al who looked at seven controls and 35 patients with coronary artery disease and found that the normal limits of the standard deviation of phase were $12^{\circ}$ at rest and $10^{\circ}$ during dynamic exercise, with a sensitivity of $95 \%$ for the detection of disease. ${ }^{6}$ Eight of the patients, however, had previous myocardial infarction and so this was not a homogeneous group. It is not surprising that a technique that detects abnormalities of ventricular wall motion should be sensitive in detecting disease in patients with infarction.

Vos et al studied 75 patients at rest only and tested the ability of quantitative phase analysis to detect regional abnormalities that were seen on the cine display of the radionuclide ventriculogram. ${ }^{7}$ They found the standard deviation of phase to be sensitive but skewness to be unhelpful. Mean normal standard deviation of phase was slightly lower than other studies at $4.7^{\circ}$, which may be explained by the way in which they corrected for heart rate by varying the cycle length. Mean normal skewness was similar to this study at -0.09 .

Norris et al studied 17 patients with coronary artery disease without infarction at submaximal and maximal exercise. ${ }^{9}$ They found similar sensitivities of ejection fraction and standard deviation of phase at maximal exercise $(53 \%$ and $59 \%$ respectively) and that combining the two gave a sensitivity of $76 \%$. These figures parallel our own, although the generally lower values reflect the wide range of sensitivities reported for the detection of coronary artery disease. ${ }^{18}$ Unfortunately, they do not say what stage of exercise is regarded as submaximal, and it is not possible to compare their submaximal data with our own.

Our results, however, do not accord with the findings of Turner $e t$ al who found that the standard deviation of phase was not sensitive in the detection of coronary artery disease but that skewness was. ${ }^{8}$ Mean resting standard deviation of phase was $8.4^{\circ}$ with similar changes in controls and those with coronary artery disease, but mean normal skewness at rest was -0.55 (significantly different from this and other studies) decreasing to -0.71 with exercise in controls but increasing to +0.03 in coronary artery disease. This discrepancy is difficult to explain unless it is attributable to differing study populations or different methods of calculating phase. To cope with rate related changes in cycle length, Turner $e t$ al included only the first $500 \mathrm{~ms}$ of the cycle if the heart rate was under $120 /$ minute and the whole cycle if it was over $120 /$ minute. This unconventional method of calculating phase is likely to affect findings in a way that is difficult to predict theoretically. Their suggestion that skewness is sensitive in the detection of disease is unexpected. Although a small area of abnormal phase may skew the phase distribution to higher values, a large area of abnormal phase will skew it to low values with the normal values being in the asymmetric tail on the left. The weight of evidence is that neither skewness nor kurtosis is helpful in detecting coronary artery disease.

\section{SUBMAXIMAL EXERCISE}

An interesting finding of this study was that the predictive accuracies of both ejection fraction and standard deviation of phase were greater at the stage before maximal exercise than at maximal exercise. It is often considered that maximal exercise is important for high sensitivity of exercise testing in coronary artery disease, but for exercise radionuclide ventriculography this may be counterproductive. Despite measures to immobilise the upper body during exercise, motion artefact will decrease the measured ejection fraction. This effect will be greatest at the higher levels of exercise achieved in the normal subjects and will reduce specificity but have a lesser effect upon sensitivity. Table 3 shows that sensitivity is not reduced at submaximal exercise but that specificity is greatly increased. Schneider et al evaluated changes in ejection fraction at each stage of exercise $^{19}$ and although they did not analyse their findings in this way, their data show a higher specificity at the stage before maximal exercise $(59 \%$ $v 41 \%$ ) with only a small reduction in sensitivity $(78 \% v 80 \%)$. They do not mention, however, that the "up-down" pattern of ejection fraction may in some cases be artefactual. Their specificity is lower than in the present study but there is a wide range of reported values, which is probably explained by 
patient selection. For instance, Schneider et al had a much higher number of patients with single vessel disease.

The effect of motion upon the phase image is harder to predict but it may reduce the standard deviation of phase, since any regional abnormality will be spread across the image. This effect may have been seen by Bacharach et al who found a direct relation between standard deviation of phase and heart rate in controls. ${ }^{20}$ While it is not certain that the observation was caused by motion artefact, it seems likely. If motion does reduce the standard deviation of phase, then a lower sensitivity for disease would be expected at maximum exercise, which fits with our observations.

If maximal exercise is not the ideal level for the detection of abnormality, then a compromise has to be chosen at a sufficiently high level for ischaemia to be induced but before the data are degraded by artefact. The operator can best decide at which stage ST segment changes or pain begin and whether there is untoward motion. If appreciable artefact is suspected, an examination of the trend of ejection fraction or wall motion changes at each stage is helpful. If there is a precipitous drop in ejection fraction in the final stage of exercise in a subject who has no other signs of disease, then a lower stage of exercise may be more reliable. Abnormalities of ventricular function occur at an early stage of myocardial ischaemia, and nearly always before the onset of chest pain. ${ }^{21}{ }^{22}$ The stage before maximal exercise seems to be a suitable compromise in routine practice.

\section{ISOMETRIC EXERCISE}

Because of the problem of motion, isometric exercise has been considered an attractive alternative to dynamic exercise, especially for patients with claudication or for those who are unable to exercise for other reasons. The haemodynamic effects of isometric exercise have been studied previously. In healthy individuals, heart rate, blood pressure, and cardiac output increase, whereas left ventricular end diastolic pressure and stroke volume decrease or are unaltered. In patients with coronary artery disease, left ventricular end diastolic pressure increases and there is often a reduction in ejection fraction. ${ }^{23-25}$ The pressor response seems to be caused by a rate dependent increase in cardiac output with unchanged peripheral vascular resistance. ${ }^{20}$ In contrast, the cold pressor response is the result of a sympathetically mediated increase in peripheral vascular resistance. ${ }^{27}$

Unfortunately, our study showed that the changes induced in ejection fraction by isometric exercise are small and in most cases they are inside the limits of reproducibility, which is \pm 6 percentage units. ${ }^{23}$ Whatever the definition of a normal ejection fraction response, therefore, the test cannot have a high predictive accuracy. New wall motion abnormalities were induced in three patients, and this was highly specific for the presence of disease. Clearly, the phase image is able to detect small changes in regional wall motion that do not produce changes of ejection fraction.

There is some dispute in published reports about the sensitivity of isometric exercise for the detection of coronary artery disease. Early studies by Bodenheimer et al found isometric exercise to be $91 \%$ sensitive and $87 \%$ specific according to the regional ejection fraction image, ${ }^{29} 30$ whereas Peter and Jones found it to have very low sensitivity when the global ejection fraction was used. ${ }^{31}$ The sensitivity of the ejection fraction to cold pressor stress is similarly low. ${ }^{32}$ The high sensitivity of the regional ejection fraction image is unexpected because it is a method of displaying regional wall motion and most workers agree that the incidence of new abnormalities is low. In our study, for instance, new abnormalities were induced in three $(17 \%)$ of 18 patients although abnormalities were also present at rest in nine $(50 \%)$ out of 18. The sensitivity is obviously dependent upon the population studied, and if there is a high incidence of resting abnormalities, the sensitivity of isometric exercise will appear to be high.

\section{THE WEIGHTED HISTOGRAM}

The phase histogram used in this study was unprocessed, with all pixels having equal weight. Bacharach et al have shown that the effect on the histogram of statistical errors in phase values can be eliminated by error weighting, where the weight that each pixel contributes to the histogram is weighted according to the error calculation of its phase..$^{33}$ The error in calculating phase is closely related to the number of counts in the pixel at end diastole. In this way, the range of normal for the standard deviation of phase is reduced and the histogram may be more sensitive in detecting abnormalities. Another technique that may increase sensitivity is "cluster weighting", in which pixels that have surrounding pixels of similar phase are given more weight. The effect of random variations in phase is eliminated and regional abnormalities may be detected more easily.

\section{THE AMPLITUDE IMAGE}

Changes in the amplitude image between rest and stress were not considered in this study. Part of the reason is that the amplitude image is usually interpreted visually since, although normal regional values can be established, the range of normal is large. We have seen that visual interpretation of the phase and amplitude images together resulted in a $63 \%$ sensitivity for the detection of disease but when 
the amplitude image alone was used this fell to $52 \%$. Vos et al found that mean amplitude was the most valuable variable for detecting abnormal wall motion, with standard deviation of phase also being an independent predictor. ${ }^{7}$ This was in patients with resting abnormalities, however, and it appears that reversible ischaemia leads to greater abnormalities of phase than of amplitude. In impending myocardial infarction, for instance, areas with delayed contraction but normal amplitude may be salvageable by reperfusion but areas with reduced amplitude are not. ${ }^{34}$

Figure 2 shows the usual pattern of stress induced ischaemia with a comparatively minor amplitude abnormality despite an obvious phase abnormality, which is the usual pattern. An example of the opposite has been described in a patient with a large stress induced amplitude defect and less important phase abnormalities. ${ }^{35}$ The conclusion is that while the phase image is very sensitive in the detection of abnormalities of the timing of ventricular wall motion, the extent of wall motion is an independent variable, and the amplitude and phase images should always be interpreted together.

\section{Conclusions}

The left ventricular ejection fraction and the standard deviation of left ventricular phase have the same predictive accuracy for the presence of disease when measured during submaximal exercise $(89 \%)$, but this accuracy is lower at maximal exercise $(77 \%)$. This reduction is probably the result of motion artefact at high exercise levels, and it leads to reduced specificity $(68 \%)$ despite maintained sensitivity $(85 \%)$. Skewness and kurtosis of the phase histogram are of no value in the detection of disease. Isometric exercise is of very limited value for the detection of disease since changes in ejection fraction are small and variable; however, wall motion abnormalities induced by isometric exercise are specific for the presence of disease.

The phase histogram provides an objective measurement of the synchronicity of left ventricular contraction and can increase sensitivity for the detection of abnormality. Data should be acquired at all stages of dynamic exercise, and the penultimate stage should be used if there is any doubt about the validity of the final stage.

We thank the Sir Jules Thorn Charitable Trust for financial support.

\section{References}

1 Becker LC. Diagnosis of coronary artery disease with exercise radionuclide imaging: state of the art. Am J
Cardiol 1980;45:1301-4.

2 Bonow RO, Kent KM, Rosing DR, et al. Exerciseinduced ischaemia in mildly symptomatic patients with coronary artery disease, and preserved left ventricular function: identification of subgroups at high risk for death during medical therapy. $N$ Engl J Med 1984;311:1339-45.

3 Pryor DB, Harrell FE Jr, Lee KL, et al. Prognostic indicators from radionuclide angiography in medically treated patients with coronary artery disease. $\mathrm{Am} \mathrm{J}$ Cardiol 1984;53:18-22.

4 Adam WE, Tarkowska A, Bitter F, Stauch M, Geffers H. Equilibrium gated radionuclide ventriculography. Cardiovasc Radiol 1979;2:161-73.

5 Walton S, Yiannikas J, Jarritt PH, Brown NJG, Swanton RH, Ell PJ. Phasic abnormalities of left ventricular emptying in coronary artery disease. $\mathrm{Br}$ Heart J 1981;46:245-53.

6 Ratib O, Henze E, Schön H, Schelbert HR. Phase analysis of radionuclide ventriculograms for the detection of coronary artery disease. Am Heart J 1982;104:1-12.

7 Vos PH, Vossepoel AM, Pauwels EKJ. Quantitative assessment of wall motion in multiple-gated studies using temporal Fourier analysis. $J \mathrm{Nucl}$ Med 1983;24:388-96.

8 Turner DA, Shima MA, Ruggie N, et al. Coronary artery disease: detection by phase analysis of rest/ exercise radionuclide angiocardiograms. Radiology 1983;148:539-45.

9 Norris SL, Slutsky RA, Gerber KH, Geiss KR, Ashburn WL, Higgins CB. Sensitivity and specificity of nuclear phase analysis versus ejection fraction in coronary artery disease. Am J Cardiol 1984;53: 1547-52.

10 Weatherburn CE. A first course in mathematical statistics. Cambridge: University Press, 1968:12-6.

11 Pearson $\mathrm{K}$. On the moments of the hypergeometrical series. Biometrika 1924;16:157-62.

12 Goris ML, Briandet PA, Huffer E. Automation and operator independent data processing of cardiac and pulmonary functions: role, methods, and results. In: Di Paolo R, Kahn E, eds. Information processing in medical imaging. Proceedings of the 6th international conference. Paris: INSERM, 1979:88:427-48.

13 Borer JS, Bacharach SL, Green MV, Kent KM, Epstein SE, Johnston GS. Real-time radionuclide cineangiography in the noninvasive evaluation of global and regional left ventricular function at rest and during exercise in patients with coronary artery disease. N Engl J Med 1977;296:839-44.

14 Borer JS, Kent KM, Bacharach SL, et al. Sensitivity, specificity and predictive accuracy of radionuclide cineangiography during exercise in patients with coronary artery disease. Comparison with exercise electrocardiography. Circulation 1979;60:572-80.

15 Berger HJ, Reduto LA, Johnstone DE, et al. Global and regional left ventricular response to bicycle exercise in coronary artery disease. Assessment by quantitative radionuclide angiocardiography. $\mathrm{Am} \mathrm{J} \mathrm{Med} \mathrm{1979;}$ 66:13-21.

16 Bodenheimer MM, Banka VS, Fooshee CM, Helfant 
RH. Comparative sensitivity of the exercise electrocardiogram, thallium imaging and stress radionuclide angiography to detect the presence and severity of coronary heart disease. Circulation 1979;60:1270-8.

17 Austin EH, Cobb FR, Coleman RE, Jones RH. Prospective evaluation of radionuclide angiocardiography for the diagnosis of coronary artery disease. Am J Cardiol 1982;50:1212-6.

18 Beller GA. Nuclear cardiology: current indications and clinical usefulness. Curr Probl Cardiol 1985;10:3-76.

19 Schneider RM, Weintraub WS, Klein LW, et al. Multistage analysis of exercise radionuclide angiography in coronary artery disease. Am J Cardiol 1986;58:36-41.

20 Bacharach SL, Green MV, de Graaf CN, van Rijk PT, Bonow RO, Johnson GS. Fourier phase distribution maps in the left ventricle: toward an understanding of what they mean. In: Esser PD, ed. Functional mapping of organ systems and other computer topics. New York: Society of Nuclear Medicine, 1981:139-48.

21 Upton MT, Rerych SK, Newman GE, Port S, Cobb FR, Jones RH. Detecting abnormalities in left ventricular function during exercise before angina and ST segment depression. Circulation 1980;62:341-9.

22 Hugenholtz PG, Lubsen J. Unstable angina pectoris in focus. In: Richardson RG, ed. Cardiovascular Focus. Newbury: Bayer UK Ltd, 1986:24:1-5.

23 Helfant R, DeVilla M, Meister S. Effect of sustained isometric exercise on left ventricular performance. Circulation 1971;44:982-7.

24 Kivowitz C, Parmley W, Donoso D, Marcus H, Ganz W, Swan HJC. Effect of isometric exercise on left ventricular performance: the grip test. Circulation 1971;44:994-1000.

25 Slutsky R. Response of the left ventricle to stress: effects of exercise, atrial pacing, afterload stress, and drugs. Am J Cardiol 1981;47:357-64.

26 Ewing DJ. Cardiovascular reflexes and autonomic neuropathy. Clin Sci Mol Med 1978;55:321-7.

27 Greene MA, Boltax AJ, Lustig GA, Rogow E. Circulatory dynamics during the cold pressor test. $\mathrm{Am} \mathrm{J}$ Cardiol 1965;16:54-60.

28 Underwood SR, Walton S, Ell PJ, Emanuel RW, Swanton RH. Isometric exercise in the detection of coronary artery disease- specific but not sensitive. In: Hoefer $\mathbf{R}$, Bergman $\mathrm{H}$, eds. Radioactive isotopes in clinical medicine and research. Vienna: Verlag $\mathrm{H}$ Egermann, 1984:16:443-50.

29 Bodenheimer MM, Banka VS, Fooshee CM, Gillespie JA, Helfant RH. Detection of coronary heart disease using radionuclide determined regional ejection fraction at rest and during handgrip exercise: correlation with coronary arteriography. Circulation 1978;58: 640-8.

30 Bodenheimer MM, Banka VS, Fooshee CM, Herman GA, Helfant RH. Comparison of wall motion and regional ejection fraction at rest and during isometric exercise: concise communication. $J$ Nucl Med 1979; 20:724-32.

31 Peter CA, Jones RH. Effects of isometric handgrip and dynamic exercise on left ventricular function. $J$ Nucl Med 1980;21:1131-8.

32 Verani MS, Zacca NM, DeBauche TL, Miller RR, Chahine RA. Comparison of cold pressor and exercise radionuclide angiography in coronary artery disease. $J$ Nucl Med 1982;23:770-6.

33 Bacharach SL, Green MV, Bonow RO, deGraaf CN, Johnston GS. A method for objective evaluation of functional images. $J$ Nucl Med 1982;23:285-90.

34 Gibson D, Mehmel H, Schwarz F, Li K, Kübler W. Changes in left ventricular regional asynchrony after intracoronary thrombolysis in patients with impending myocardial infarction. Br Heart J 1986;56:121-30.

35 Underwood SR, Walton S, Ell PJ. Paradoxical phase changes induced by myocardial ischaemia. Nucl Med Commun 1985;6:225-8. 